\title{
Recent advances in bio-based multi-products of agricultural Jerusalem artichoke resources
}

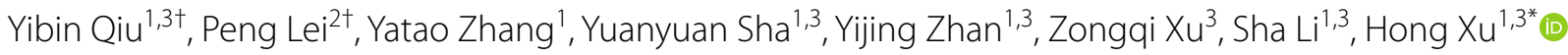 \\ and Pingkai Ouyang ${ }^{1,3}$
}

\begin{abstract}
The Jerusalem artichoke is a perennial plant that belongs to the sunflower family. As a non-grain crop, Jerusalem artichoke possesses a number of desirable characteristics that make it a valuable feedstock for biorefinery, such as inulin content, rapid growth, strong adaptability, and high yields. This review provides a comprehensive introduction to renewable Jerusalem artichoke-based biomass resources and recent advances in bio-based product conversion. Furthermore, we discuss the latest in the development of inulinase-producing microorganisms and enhanced inulin hydrolysis capacity of microbes by genetic engineering, which lead to a more cost-effective Jerusalem artichoke biorefinery. The review is aimed at promoting Jerusalem artichoke industry and new prospects for higher valueadded production.
\end{abstract}

Keywords: Jerusalem artichoke, Inulin, Inulinase, Non-grain fermentation, Biorefinery

\section{Background}

Concerns over fossil fuels depletion and environmental protection have attracted increasing worldwide interest in the development and utilization of sustainable and taintless energy resources. A sunflower species native to North America, Helianthus tuberosus L., also known as the Jerusalem artichoke, is a potential source of renewable energy [1]. Meanwhile, the increasing use of chemical fertilizers and development of irrigation agriculture have led to the constant expansion of secondary salinization land area [2]. Because of more tolerance to harsher conditions than that of most commercial crops, Jerusalem artichoke was selected and developed for large-scale cultivation in saline-alkaline soils or coastal shoals [3, 4]. Therefore, the establishment of this cover crop in noncultivatable land can reap both ecological and economic benefits.

\footnotetext{
*Correspondence: xuh@njtech.edu.cn

${ }^{\dagger}$ Yibin Qiu and Peng Lei contributed equally to this work

${ }^{1}$ College of Food Science and Light Industry, Nanjing Tech University,

Nanjing 211816, China

Full list of author information is available at the end of the article
}

In addition to its unique value in ecological environment improvement, inulin-rich Jerusalem artichoke serves as an important raw material in the food, chemical, and pharmaceutical industries (Fig. 1) $[5,6]$. A promising candidate, Jerusalem artichoke exhibits many advantages for biorefinery. Compared with traditional grain crops, the Jerusalem artichoke produces large amounts of biomass and can be harvested three times a year [7]. Furthermore, the inulin found in Jerusalem artichoke tubers can be easily processed using available technologies, and can be suitable as a substrate for biorefinery. More importantly, the non-food utilization of this biofuel crop does not compete for arable land with grain crops cultivated for food production [8]. This review aims to provide a comprehensive overview on the characteristics of Jerusalem artichoke and the pretreatment process for biorefinery, as well as a description of inulinase-producing microorganisms and inulinase catalytic mechanisms that will provide fundamental knowledge for inulin biorefinery studies. Furthermore, recent advances in Jerusalem artichoke research and development of bioproducts derived from these artichokes are summarized. 


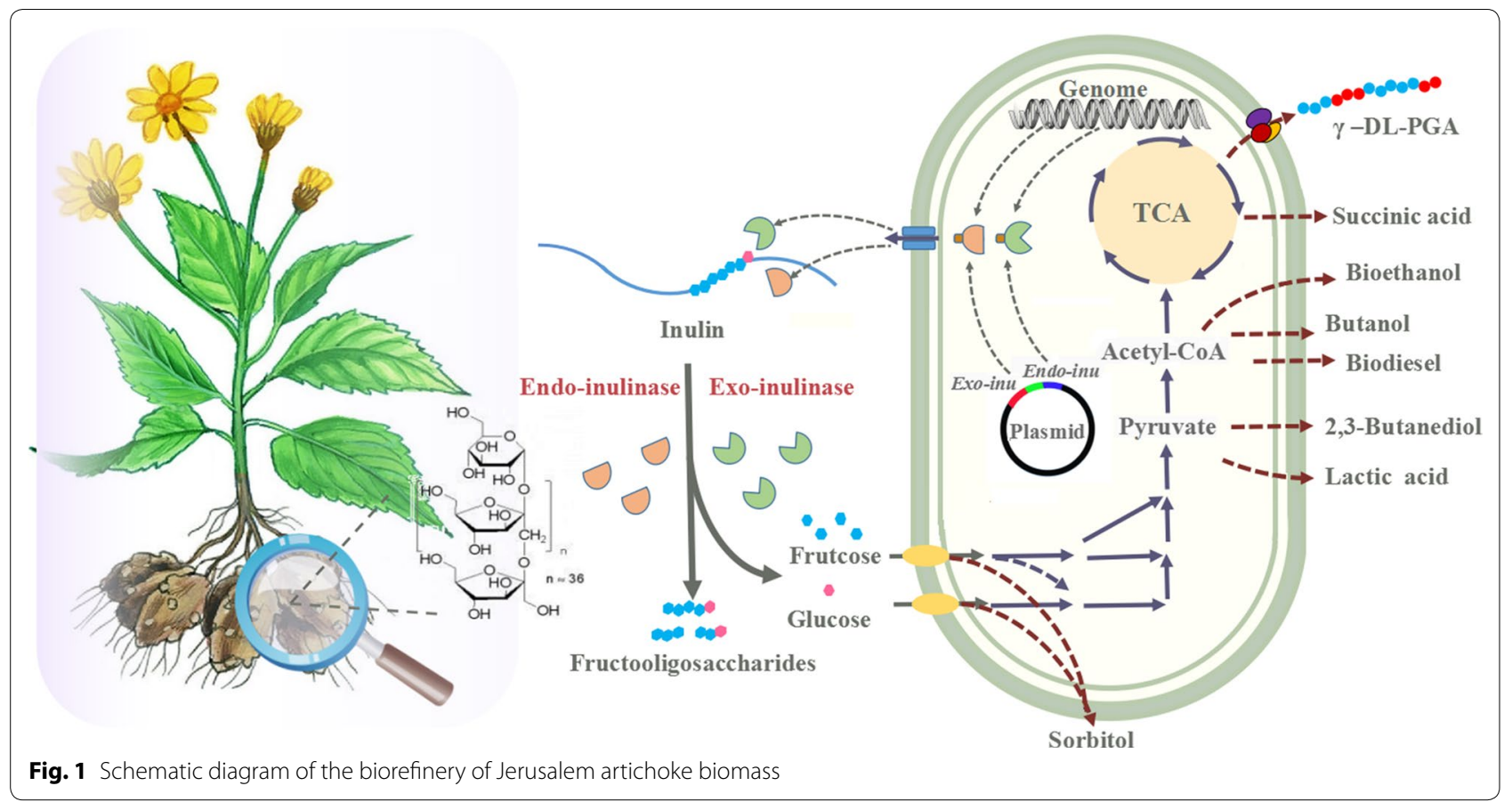

Finally, we discuss the prospects of energy crops in future biological manufacturing.

\section{Overview of the Jerusalem artichoke resource Jerusalem artichoke features}

Jerusalem artichoke (Helianthus tuberosus) is a perennial herbaceous plant that belongs to the Compositae family $[9,10]$. Due to its strong adaptability, Jerusalem artichoke is widely distributed in China as a cultivated crop [11]. Morphologically, the Jerusalem artichoke is large, gangly, and highly branched with yellow flower heads. The young stems are stout and can grow $100-300 \mathrm{~cm}$ tall. It has opposite leaves on the lower part of the stem that are roughly $10-20 \mathrm{~cm}$ long and $5-10 \mathrm{~cm}$ in width, and are believed to be important for tuber yields [12]. The Jerusalem artichoke has a hairy and fibrous root system which can grow as long as $127 \mathrm{~cm}$, showing strong environmental tolerance and effective acquisition of soil nutrients [13]. The tubers are irregularly spherical or spindle shaped and vary in color from pale brown to white, red, or purple [14]. As an easily grown crop, it endures a wider range of temperatures and can tolerate $\mathrm{pH}$ levels ranging from 4.5 to 8.2 [13]. In addition, cultivation of Jerusalem artichoke does not need too much management and protection due to its strong resistance to pests and plant diseases [15]. It can be harvested annually after planting, leading to high yields of fresh weight $(90 \mathrm{t})$ per hectare that can be used as a sustainable biomass feedstock for biorefinery [16].

\section{Jerusalem artichoke components}

Jerusalem artichoke is a semi-wild plant resource with a great potential for development. Jerusalem artichoke tubers, which are mainly used during processing comprise $75.88 \%$ water, $12.46 \%$ total sugar, $1.58 \%$ total protein $(\mathrm{w} / \mathrm{w}), 1.77 \%$ total fat, and other microelements as well as vitamins [17]. Among them, inulin accounted for $80 \%$ of the carbohydrates found in tubers (Table 1) [14, 16]. Generally, differences among cultivars, harvest periods, production conditions, postharvest storage, and processing methods result in variations. As a main component of tubers, inulin is a storage polysaccharide found in many plants. The inulin mostly consists of D-fructose bonded

Table 1 Chemical composition of Jerusalem artichoke. Data from Kaldy et al. [17]

\begin{tabular}{ll}
\hline Ingredient & $\begin{array}{l}\text { Content } \\
\text { (\% of fresh } \\
\text { weight) }\end{array}$ \\
\hline Water & 75.88 \\
Dry mass & 24.12 \\
Total sugar & 12.46 \\
Total protein & 1.58 \\
Total fat & 1.77 \\
P, K, Ca, Mg, Fe & 0.50 \\
Vitamin A (I.U. in fresh weight) & 37 \\
Vitamin C (mg/100 g fresh weight) & 0.82 \\
\hline
\end{tabular}


by $(2 \rightarrow 1) \beta$-linkages that are terminated by $\mathrm{D}$-glucose molecules bonded to fructose by $(2 \rightarrow 1) \alpha$-bonds. The degree of polymerization (DP) of standard inulin ranges from 2 to 60 and the average molecular weight is approximately $5500 \mathrm{Da}$ [18]. Besides the presence of abundant fermentable polysaccharides, the Jerusalem artichoke is rich in amino acids, B vitamins, and a variety of minerals that are advantageous for multiproduct biorefineries.

\section{Jerusalem artichoke pretreatment}

An efficient inulin extraction process is important to ensure the successful utilization of Jerusalem artichoke in many fields. Fresh tubers are washed, dried, and ground into a crude powder using a crushing machine over a 40-mesh screen. Due to the high solubility of inulin in hot water, extracting inulin from the powder only requires a straightforward hot water extraction technique. Wei et al. optimized the conditions by using a neutral $\mathrm{pH}$ for $20 \mathrm{~min}$ at $76.65{ }^{\circ} \mathrm{C}$ and solvent:solid ratios of $10.56: 1(\mathrm{v} / \mathrm{w})$; an inulin extraction yield of $83.6 \%$ was obtained [19]. Yi et al. extracted inulin from fresh, frozen, or dry tubers through hot water extraction, and showed that the highest yield of 93\% was obtained from Jerusalem artichoke powder [20]. When Jerusalem artichoke is used in industrial biorefinery, the inulin extract is firstly degraded into fermentable sugars for microbial utilization through acid or enzyme hydrolysis. Acid hydrolysis is an early method for inulin hydrolysis. The acid hydrolysis of inulin has been investigated utilizing mainly sulfuric or hydrochloric acid. Nasab et al. investigated the effects of $\mathrm{pH}$, temperature, and time on acid hydrolysis of inulin and the maximum amount of inulin hydrolysis ( $>90 \%$ ) was obtained at the $\mathrm{pH}<2$, temperature $>90^{\circ} \mathrm{C}$ and the time of $1 \mathrm{~h} \mathrm{[21].} \mathrm{Xu} \mathrm{et} \mathrm{al.} \mathrm{obtained} 92.3 \%$ of the total sugars $(20.2 \pm 0.1 \mathrm{~g} / \mathrm{L}$ of glucose and $87.5 \pm 0.3 \mathrm{~g} / \mathrm{L}$ of fructose) from $120 \mathrm{~g} / \mathrm{L}$ inulin hydrolyze with $5 \%(\mathrm{w} / \mathrm{w})$ $\mathrm{HCl}$ at $60{ }^{\circ} \mathrm{C}$ for $1 \mathrm{~h}$ [22]. Therefore, acid hydrolysis of inulin has lower cost and proceeds faster. However, acid hydrolysis results in colored by-products and inhibitors that interfere with microbial growth [23]. And nowadays, more and more attentions are paid to the development of green production technology, and acid hydrolysis is not fit with this idea. So, researchers begin to focus on the enzyme hydrolysis. Inulinase is the most commonly used for inulin hydrolysis. Sarchami et al. optimized the enzymatic hydrolysis of inulin from Jerusalem artichoke tubers and the $94.5 \%$ of the inulin conversion was achieved at $48{ }^{\circ} \mathrm{C}$ for $48 \mathrm{~h}$ with the inulinase loading of 10 units g/inulin [24]. Singh et al. used immobilized yeast inulinase for the hydrolysis of inulin in a batch system and maximum hydrolysis of inulin $84.5 \%$ was observed at $125 \mathrm{rpm}$ after $4 \mathrm{~h}$ [25]. Szambelan et al. compared the acid and enzymatic hydrolysis in Jerusalem artichoke tubers pretreatment and showed that acid and inulinase hydrolysis produced 178.8 and $68.8 \mathrm{~g}$ reducing sugars per $\mathrm{kg}$ wet matter of tuber for $1 \mathrm{~h}$, respectively [26]. Compared with acid hydrolysis, enzymatic hydrolysis has mild reaction, less by-products, no pigmentation, and is easier to separate and refine. Furthermore, the unique advantage of enzymatic method is that it can simultaneously combine hydrolysis and fermentation in Jerusalem artichoke biorefinery, which shorten the overall time and improve the productivity [27]. In addition, some microorganisms can directly produce inulinases to hydrolyze inulin and avoid the addition of enzymes during refining, which greatly reduces the cost $[28,29]$. With the popularity of green production technology, the use of enzymatic degradation of inulin has become a major trend in the industry. After hydrolysis, the composition of Jerusalem artichoke hydrolysate was determined using the method previously described by Kaldy et al. [17].

\section{Microbial inulinases for biorefinery}

During the process of Jerusalem artichoke biorefining, degradation of inulin into fermentable sugars for microbial utilization is the key step. Inulin is mainly broken down through acid hydrolysis and enzymatic hydrolysis into fermentable sugars for biorefinery. Compared with acid hydrolysis of inulin, inulinase hydrolysis has the advantages of less by-products, no pigmentation, and is easier to separate and refine, which is more suitable for fermentation production. As a type of furan fructose hydrolase, inulinase can act on the $\beta-2,1$ glycosidic bond, converting inulin into glucose, fructose, or inulooligosaccharides [30]. The main commercial source of inulinase is microorganisms due to the ease of largescale cultivation and their high inulin hydrolysis activity. At present, inulinase-producing microorganisms can be screened using a plate assay as previously described by Castro et al. [31]. Table 2 lists the high inulinase activity of different inulinase-producing microorganisms. To isolate inulinase overproducers, a number of inulinaseproducing strains have been reported. Kango et al. isolated a new strain, Aspergillus niger NK-126, and used dandelion tap root extract as the medium substrate for inulinase production; inulinase activity reached a final concentration of $55.0 \mathrm{U} / \mathrm{mL}$ after $96 \mathrm{~h}$ of fermentation [32]. Ge et al. obtained the mutant strain A. niger SL-09 by using UV light and $\mathrm{LiCl}$, whose inulinase 160 activity increased nearly twofold $(150 \mathrm{U} / \mathrm{mL})$. For the A. niger SL-09 strain, the culture medium was further optimized by using sucrose ester that can act as an effective inducer of inulinase synthesis; the highest inulinase activity reached $230 \mathrm{U} / \mathrm{mL}$ after $96 \mathrm{~h}$ of shake flask fermentation at $30^{\circ} \mathrm{C}$ with $140 \mathrm{rpm}$ [33]. Moreover, yeast strains were also proven as another predominant inulinase producer. 


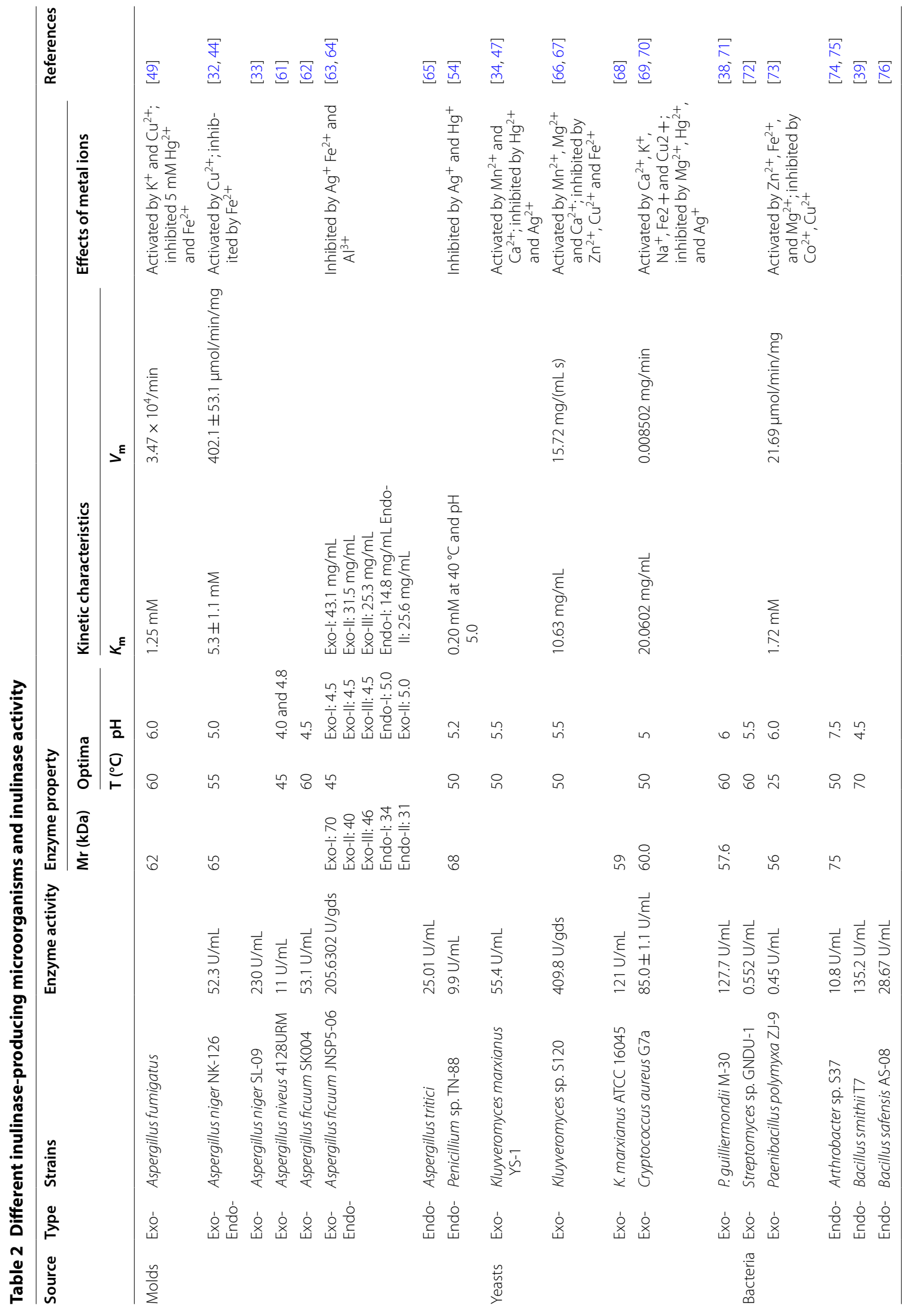


Kluyveromyces marxianus is the most common inulinase producer that has been studied extensively. A recently isolated strain, $K$. marxianus YS-1, was researched for its inulinase production [34]. After condition optimization, maximum inulinase activity reached $55.4 \mathrm{U} /$ $\mathrm{mL}$ after $60 \mathrm{~h}$ at an agitation rate of $200 \mathrm{rpm}$ and aeration of $0.75 \mathrm{vvm}$ when using $2 \%$ of the inulin extracted from dahlia tubers. K. marxianus ATCC 16045 was also reported to produce a large amount of inulinase (121 U/ $\mathrm{mL}$ ) and was proposed as a future inulinase overproducer in yeasts [35]. Additionally, some marine yeast were also found to efficiently synthesize inulinase. After screening over 300 marine yeast strains from different marine environments, Cryptococcus aureus G7a, a yeast found in sediments from the South China Sea, was found to produce the largest amount of extracellular inulinase. Under optimal conditions, over $85.0 \mathrm{U} / \mathrm{mL}$ of inulinase activity was produced within $42 \mathrm{~h}$ of shake flask fermentation [36]. Fang et al. selected the yeast strain, Pichia guilliermondii, from marine algae. Using optimal culture conditions, inulinase activity reached $61.5 \pm 0.4 \mathrm{U} / \mathrm{mL}$ after $48 \mathrm{~h}$ [37]. To further increase inulinase activity of the strain, mutant strain M-30, with a high inulinase activity $(115.0 \pm 1.1 \mathrm{U} / \mathrm{mL})$, was obtained after mutagenesis by $\mathrm{UV}$ and $\mathrm{LiCl}$. When using response surface methodology (RSM) to optimize composition and conditions of the medium, inulinase activity of the M-30 strain ultimately reached $127.7 \pm 0.6 \mathrm{U} / \mathrm{mL}$ [38]. Bacteria are important microorganisms in biorefinery and the inulinases they produce are stable at a wide range of $\mathrm{pH}$ values and higher temperatures, indicating application value. A thermophilic inulinase-producing strain was isolated from different soil samples using inulin as the sole carbon source and culturing at $50^{\circ} \mathrm{C}$; fermentation conditions of
Bacillus smithii $\mathrm{T} 7$ were optimized, and inulinase activity increased to $135.2 \mathrm{U} / \mathrm{mL}$ after incubating for $72 \mathrm{~h}$ [39]. This is the highest reported inulinase activity produced by bacteria thus far.

Based on the differential hydrolysis of glycosidic bonds, inulinase can be divided into exo-inulinases (E.C. 3.8.1.80) or endo-inulinases (E.C. 3.2.1.7). Exo-inulinase functions by removing individual fructose from the nonreducing end of inulin. Endo-inulinase can randomly break the $\beta-2,1$ glycosidic bonds in inulin, and can be used to produce inulotrioses (F3), inulotetraoses (F4), and other IOSs that can be designated as GFn or Fn, where G and F stand for glucose and fructose, respectively (Fig. 2) [40]. The classical method of inulinase activity determination is the Nelson-Somogyi colorimetric method [41].

\section{Catalytic properties and mechanism of exo-inulinase}

The exo-inulinase gene, INUI, was firstly cloned by Laloux et al. from K. marxianus ATCC 12424, and it had an ORF of $1668 \mathrm{bp}$ and 555 encoded amino acids [42]. Then Wen et al. reported on the gene encoding exo-inulinase from $K$. cicerisporus CBS4857, and found that the gene structure contains an ORF of 1665 bp that encodes 555 amino acids, including a signal peptide composed of 23 amino acids [43]. The properties of inulinases from different microorganisms are summarized in Table 2 . The molecular weight of exo-inulinase ranges from 40.0 to $256.0 \mathrm{kDa}$. As reported, most of the exo-inulinases derived from fungi have a greater molecular weight than $50.0 \mathrm{kDa}$, such as C. aureus $\mathrm{G7a}(60.0 \mathrm{kDa})$, P. guilliermondii strain $1(50.0 \mathrm{kDa})$, and A. niger $12(65.0 \mathrm{kDa})[36$, $37,44]$. The optimal $\mathrm{pH}$ ranges were $5.0-6.5$ for yeast exo-inulinase, 4.0-6.0 for mold exo-inulinase, and 4.57.5 for bacterial exo-inulinase. For industry application

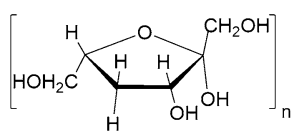

Frucose
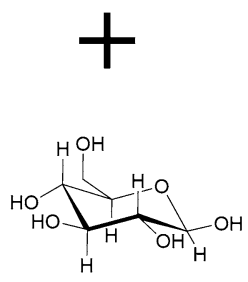

Glucose

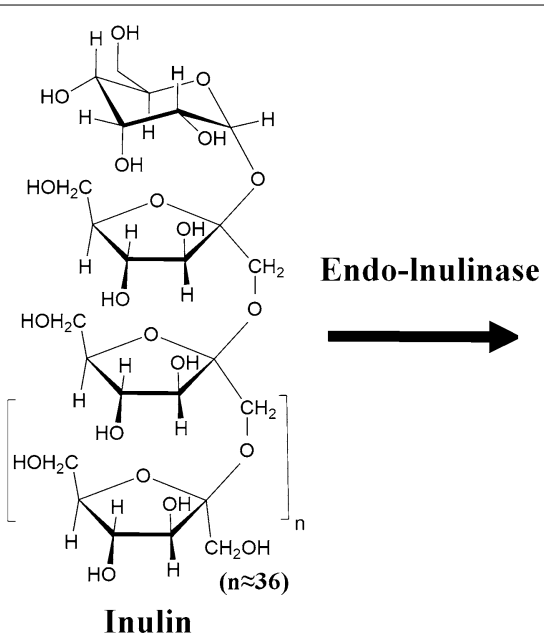

Inulin
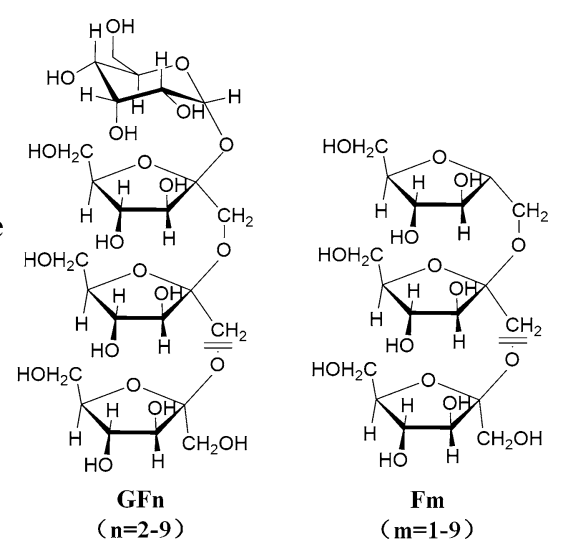

Fructooligosaccharides

Fig. 2 Two modes of action on inulin by inulinases 
and increasing solubility of inulin, thermal stability would be an advantageous property of inulinase. The optimal temperature of inulinase produced by yeast is usually $50{ }^{\circ} \mathrm{C}$ [45-47], while it was $60{ }^{\circ} \mathrm{C}$ for exo-inulinases from Aspergillus ficuum JNSP5-06 [48] and Aspergillus. fumigatus [49]. In addition, the optimal temperature for exo-inulinases produced from B. polymyxa MGL21 is $35{ }^{\circ} \mathrm{C}[50]$. The results indicate that optimal temperatures of inulinases produced by various microorganisms are different.

At present, most of works on inulinase are focused on screening of inulinase overproducers and extraction and purification of the enzyme. There are only a handful of studies on the mechanisms of inulinase. The crystal knot of exo-inulinase derived from Aspergillus awamori was determined for the first time by X-ray diffraction by Nagem et al. [51]. As a member of the G32 family of glycosyl hydrolases, exo-inulinase consists of two domains, an N-terminal comprising 353 amino acid residues (Phe20 to Gln372) and a C-terminal with 156 amino acid residues (Arg382 to Asn537). The N-terminal domain is the catalytic region of exo-inulinases and is composed of 5 leaf-like helical fold structures. In the conserved sequence 38-WMNDPNG-44 [motif A], the Asp41 residue acts as a nucleophile to attack the substrate, forming the intermediate between enzyme and substrate, and in the sequence 241-ECPGL-245 [motif F], Glu241 functions as a general acid/base catalyst that constitutes the active site of the enzyme (Fig. 3a). Arg188 and Arg189 of the E motif (RDPKV) participate in the recognition and binding of substrates. Moreover, Goosen et al. studied the C-terminal conserved G motif (SVEVF) of $A$. niger exo-inulinases and found that when Ser469 was replaced with threonine residues, hydrolysis activity of the mutant in forming sucrose, inulin, and levan, was decreased. When G motif Ser469 was replaced with the hydrophobic valine residue, the enzyme was completely inactivated. The results showed that the $G$ motif is responsible for hydrolysis of fructans and sucrose in the inulinase catalytic process [52].

\section{Catalytic properties and mechanism of endo-inulinase}

Due to the health benefits of fructooligosaccharides, the utilization of endo-inulinase to produce fructooligosaccharides from inulin is increasing. An endo-type inulinase containing 555 amino acids was purified from Penicillium sp. TN-88 [53]. The enzyme is $68.0 \mathrm{kDa}$ with a high inulinase activity at $\mathrm{pH} 5.2$ and $50{ }^{\circ} \mathrm{C}$. Hydrolysis rates reached $70 \%$ after $72 \mathrm{~h}$ and the product was mainly composed of F3. Mutanda et al. used the purified endoinulinase from $A$. niger for fructooligosaccharides production. Molecular mass of the enzyme is $68.1 \mathrm{kDa}$ and can act on inulin substrates at $\mathrm{pH} 6$ and $60^{\circ} \mathrm{C}$, producing

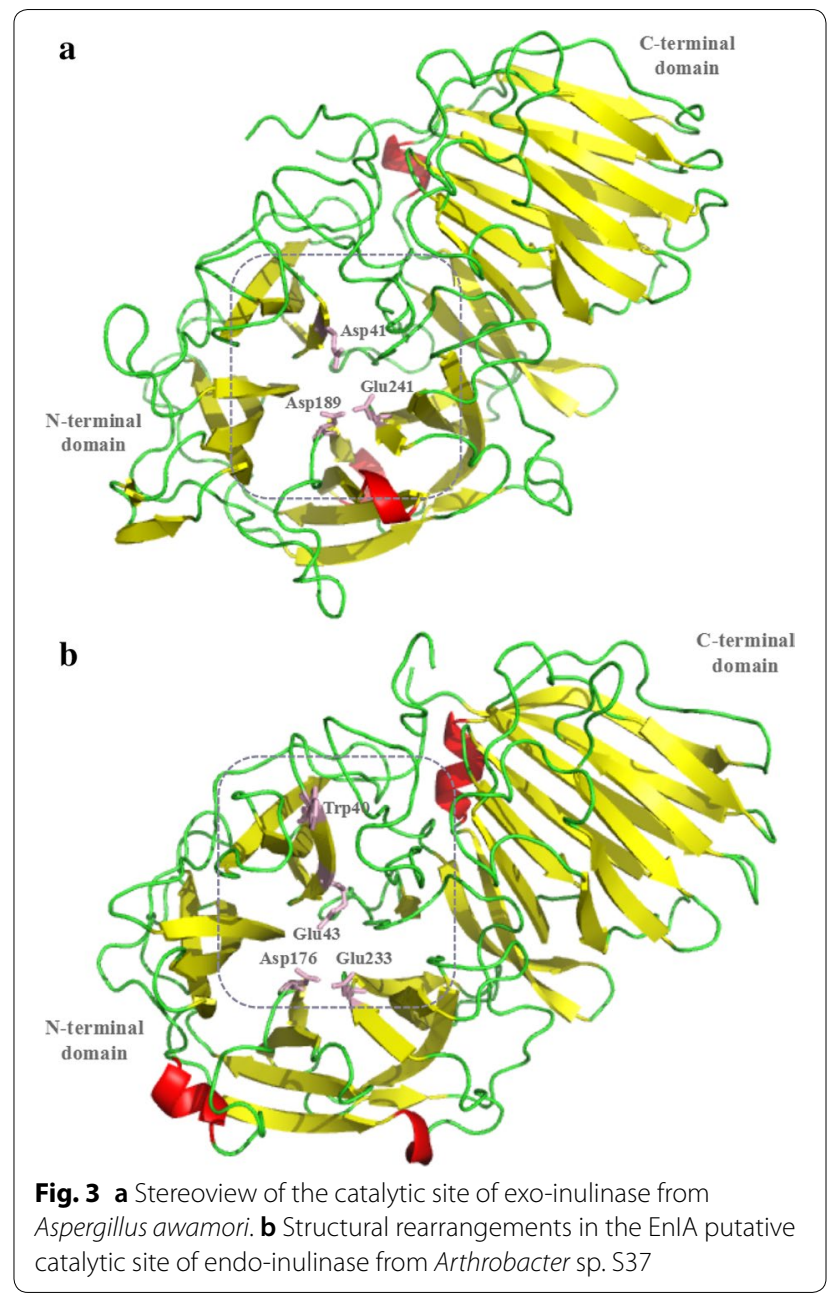

high yields of inulotrioses $(70.3 \mathrm{mM})$, inulotetraoses $(38.8 \mathrm{mM})$, and inulopentaoses $(3.5 \mathrm{mM})$ [54]. In addition, bacterial endo-inulinases were also studied; Li et al. reported that the Arthrobacter sp. S37 strain can produce endo-inulinase EnIA (2439 bp). The molecular weight is $75.0 \mathrm{kDa}$, and a $\mathrm{pH}$ of 7.5 and a temperature of $50{ }^{\circ} \mathrm{C}$ are the optimal conditions for this purified enzyme. The main products of inulin hydrolysis are inulotrioses, inulotetraoses, and inulopentaoses [55]. A novel endoinulinase-producing strain, Streptomyces rochei E87, was identified and found to degrade inulin into inulotriose as the main product with a yield of $71 \%$ [56]. In addition, Xanthomonas sp. was also implicated in inulin hydrolysis, with the inulooligosaccharide conversion rate of $93 \%$ at $\mathrm{pH} 7$, and $\mathrm{DP} \geq 5$ oligosaccharides [56, 57]. In contrast to exo-inulinases (Fig. 4), the Glu (E) residue in the motif A (WMNEPNG) of endo-inulinases has a key role in the catalytic activity of the enzyme, while the conserved region (SVEVF) is important in anchoring macromolecular glycans and attacking long chain inulin or 

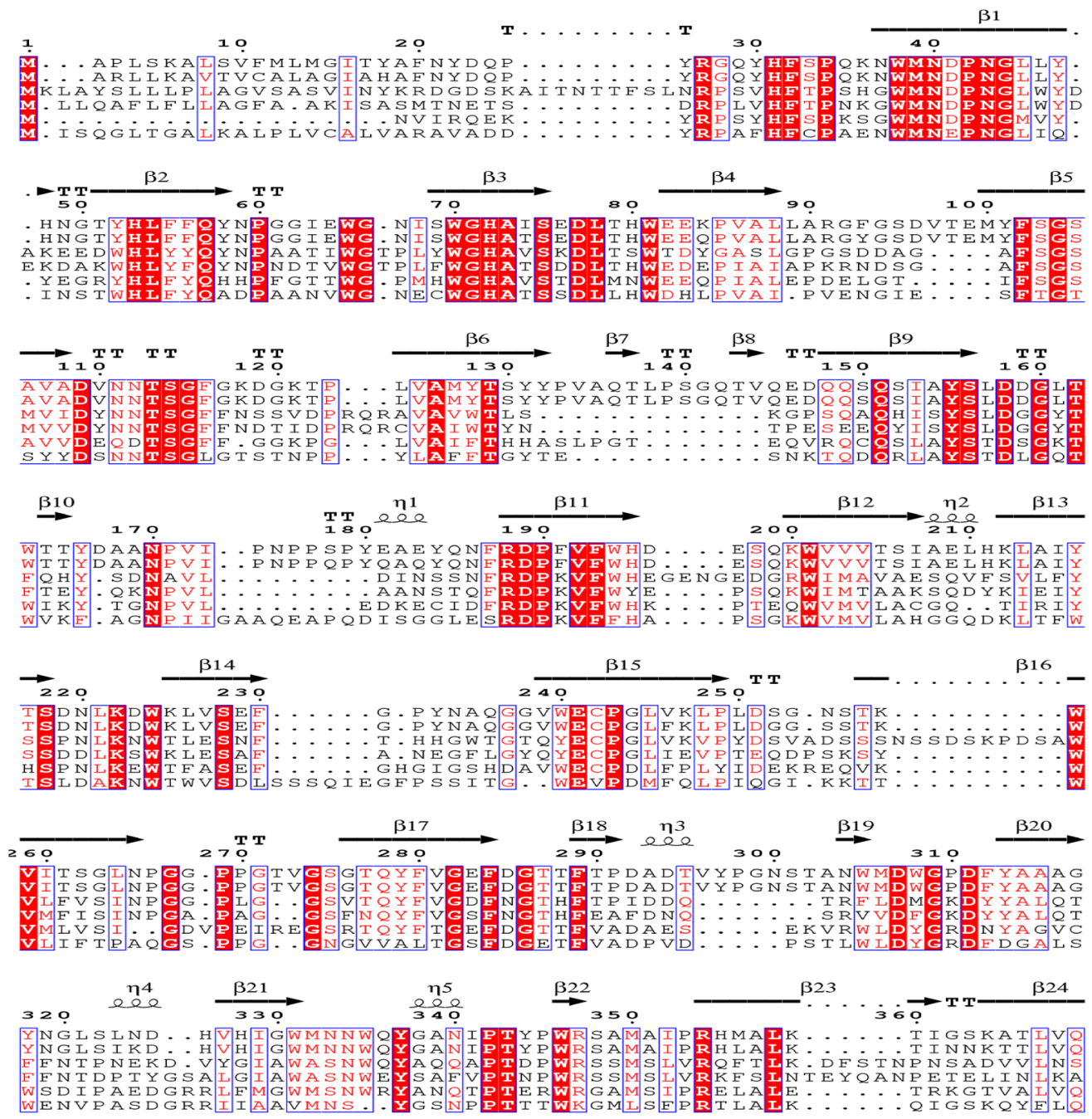

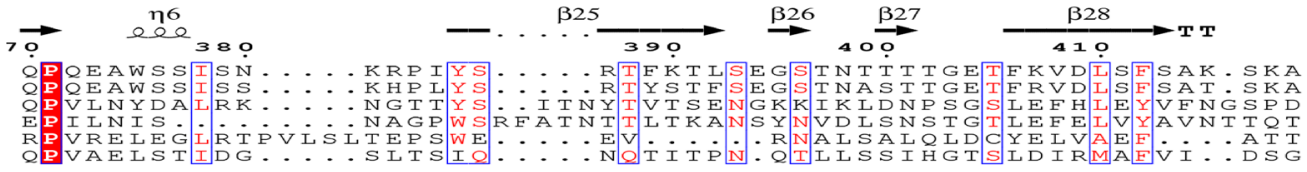

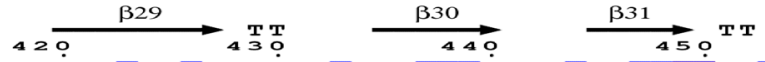

. STFATAIRASA

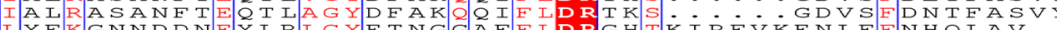

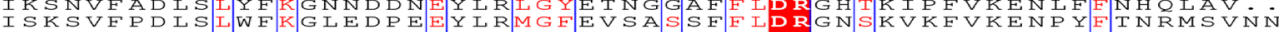

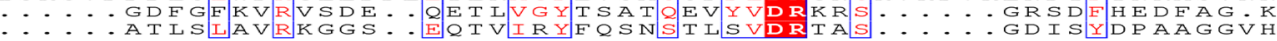

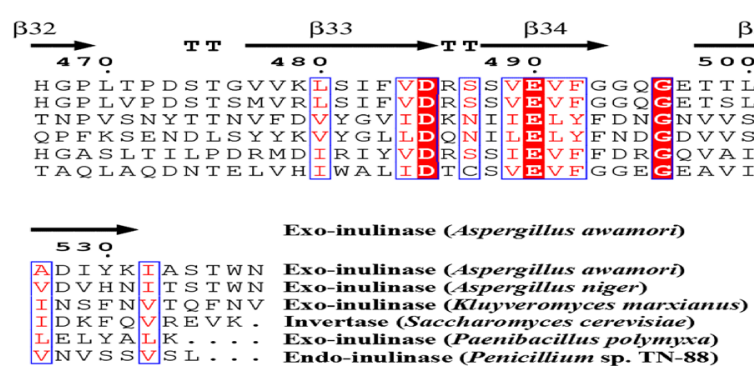

Fig. 4 Sequence alignment of inulinase representative members 
glycans (Fig. 3b) [58, 59]. Kim et al. studied the functional and catalytic mechanisms of endo-inulinases derived from Arthrobacter sp. S37. Three conserved amino acid residues (Glu323, Asp460, and Glu519) from 319-WMNDEPNGL-327 [motif A], 459-RDF-461 [motif E], and 519-ECMP-522 [motif F], respectively, were modified by site-directed mutagenesis. The $k_{\text {cat }}$ values of E323A and E519A mutants decreased, but there was no variation in $K_{\mathrm{m}}$, consistent with their putative roles as nucleophiles and acid-base catalysts. On the other hand, the D460A mutant was completely inactive. These results proved that Glu323, Asp460, and Glu519 are essential amino acids for enzyme activity [60].

\section{Research advances on the biorefinery potential of Jerusalem artichoke Fructooligosaccharides}

Fructooligosaccharides have been classified as prebiotics due to their bifidogenic nature and health-promoting properties when consumed in sufficient amounts as recommended by health practitioners [77, 78]. From an industrial point of view, FOSs are mainly enzymatically manufactured from sucrose using fructosyltransferases $(\mathrm{DP}<4)$ or by controlled enzymatic hydrolysis of inulin $(\mathrm{DP}<9)$ [79]; however, the former process is complex as several reactions occur and is inevitably accompanied by a residual of sucrose, that can lead to food-related obesity [80]. By contrast, the production of FOSs from inulin using endo-inulinases is a single-step process. Moreover, FOSs produced from inulin contain longer chains $(\mathrm{DP}=2-9)$ that have enhanced physiological activity than those synthesized from sucrose $(\mathrm{DP}=2-4)$. Recent advances in industrial enzymology have made the largescale production of FOSs from inulin possible.

It has been reported that many filamentous fungi and bacterial strains can produce endo-inulinases [81]. Endo-inulinase from pseudomonas sp. was used for FOSs $(\mathrm{DP}=2-7)$ production with a yield of $75.6 \%$ [82]. At the same time, Yun et al. reported FOSs yields of $83 \%$ from inulin by using immobilized endo-inulinase from Pseudomonas sp. The immobilized endo-inulinase reactor operated for 15 days for FOSs production without a significant loss in enzyme activity which indicated the potential of industrial application [83]. Batch-wise production of FOSs from pure inulin was performed using partially purified endo-inulinases from Xanthomonas sp. obtaining a yield of $86 \%$ and $\mathrm{DP}=5-6$ of the main product [57]. Cho et al. developed a dual endo-inulinase system from Xanthomonas sp. and Pseudomonas sp. for the maximum FOSs yields of $92 \%$ from pure inulin. In addition to FOSs production from inulin by bacterial endo-inulinases, molds are also important sources of endo-inulinase [84]. Jin et al. purified endo-inulinase from Aspergillus ficuum and achieved FOSs $(\mathrm{DP}=2-8)$ production of $80 \%$ using the Jerusalem artichoke juice as substrate after $72 \mathrm{~h}$ [85]. A newly discovered producer Aspergillus trtici BGPUP6 with $25.01 \mathrm{U} / \mathrm{mL}$ of endoinulinase was considered as a candidate for FOSs production [65]. Due to the low endo-inulinase activity by native microorganisms, recombinant endo-inulinases have been also used to produce FOSs from inulin in recent years. Yun et al. first cloned the endo-inulinase gene, INU1, from Pseudomonas sp. and expressed constitutively in Escherichia coli $\mathrm{HB} 101$ for FOSs production [86]. A yield of $78 \%$ was obtained by using immobilized cells at $50{ }^{\circ} \mathrm{C}$ and continuously operated for 17 days without endoinulinase loss. E. coli BL21 (DE3) was also used to express the endo-inulinase isolated from Aspergillus ficuum; the highest endo-inulinase enzyme activity $(75.22 \mathrm{U} / \mathrm{mg})$ was obtained and an IOS yield of $94.41 \%$ was achieved at $55{ }^{\circ} \mathrm{C}$ and $\mathrm{pH} 4.6$ for $24 \mathrm{~h}$ [87]. Although a high FOSs conversion rate was achieved in an E. coli expression system, the system's lack of safety greatly limits its application in the food industry. Kim et al. cloned INU1 from Pseudomonas mucidolens, after which the expressed endo-inulinases in Saccharomyces cerevisiae cells hydrolyzed inulin with an IOS yield of $71.2 \%$ after $30 \mathrm{~h}$; the IOSs mainly consisted of inulotetraoses [88]. On the other hand, a high yield of FOS production (91.3\%) was obtained from recombinant Pichia pastoris expressing the endo-inulinase gene (EnInu) from A. niger [89]. As an important value-added product from Jerusalem artichoke material, FOSs as function food have attracted extensive attention. By recombinant expressions of endo-inulinase, a handful of reports on the FOSs production with high yields have been presented above which exhibits great potential for industrial applications, and developments in separation of by product (glucose, sucrose) and impurity for high pure FOSs product is the need for future work. To simplify the IOS production process, highefficiency immobilization technology, novel reactors for biocatalysts should be explored to scale up to industrial production.

\section{Ethanol}

Ethanol is not only an important raw material in the chemical synthesis industry, but it is also the most promising biofuel. Among the biorefinery products of Jerusalem artichoke, ethanol has been studied extensively. However, the most commonly used alcohol production strains in the industry, S. cerevisiae and Zymomonas mobilis, cannot effectively utilize inulin to produce ethanol, which severely restricts the industrialization of ethanol production of inulin-based biomass [90]. Traditional ethanol production processes firstly convert inulin to fructose via acid hydrolysis, and then reuse the microbes 
to ferment ethanol. Onsoy et al. used the acid hydrolysates of Jerusalem artichoke juices as the media for ethanol fermentation by $Z$. mobilis, which led to consistent ethanol yields $(0.45 \mathrm{~g} / \mathrm{g})$ and a conversion efficiency of $83.19 \%$ of theoretical value [91]. The cost of inulin acid hydrolysis technology for ethanol production is low, but the process is relatively complicated as hydrolysates often contain HMF, a microbial growth inhibitor, and is not environment friendly [92]. Therefore, researchers begin to use microbes or enzymes to assist with $S$. cerevisiae in producing ethanol directly from inulin. Zhang et al. used the recombinant inulinase produced by $P$. pastoris, $X-33 / p P I C Z a A-I N U 1$, to hydrolyze inulin and ethanol fermentation by $S$. cerevisiae sp. W0. The total sugar utilization rate after $120 \mathrm{~h}$ of fermentation was $98.9 \%$, and an ethanol yield of $0.384 \mathrm{~g} / \mathrm{g}$ inulin was obtained [93]. The study further proved that inulinase pretreatment of inulin products for ethanol fermentation is feasible. Although inulinase-assisted $S$. cerevisiae ethanol production is an environmentally friendly technology, the formed fructose inhibits inulinase secretion. Therefore, to relieve product inhibition, researchers have developed a co-fermentation technology on ethanol production combined with inulinase-producing microorganisms. Through mutagenesis, Ge and Zhang obtained an inulinase-producing strain, $A$. niger SL-09, and co-cultured it with the highly ethanol-tolerant S. cerevisiae Z-06. After $48 \mathrm{~h}$ of Jerusalem artichoke fermentation, the utilization rate of inulin was $98 \%$, and the ethanol concentration reached $19.6 \%(\mathrm{v} / \mathrm{v})$ [94]. Therefore, there is a need to further optimize microbial strains and the process, by improving microbial fermentation co-culture parameters to maximize efficiency of ethanol production from inulin. Since the genome of $S$. cerevisiae is well studied and genetic manipulation techniques are more advanced, more researchers are focusing on the use of genetic engineering strategies to obtain a recombinant Saccharomyces cerevisiae with inulinase that can directly produce ethanol from inulin. Tong et al. expressed the INU1 gene from marine-derived P. guilliermondii and the recombinant Saccharomyces sp. W0 was able to produce $34.2 \mathrm{U} /$ $\mathrm{mL}$ of extracellular inulinase activity in $72 \mathrm{~h}$. During $2 \mathrm{~L}$ fermentation, $14.9 \%(\mathrm{v} / \mathrm{v})$ of ethanol was obtained with the conversion efficiency of $99.5 \%$ from inulin to ethanol [95]. Yuan et al. cloned the exo-inulinase gene from $\mathrm{Can}$ dida kutaonensis and expressed in S. cerevisiae for the improvement of inulin utilization, and the recombinant S. cerevisiae was able to produce high ethanol yields from both inulin and Jerusalem artichoke tuber flour [96]. A natural engineering $S$. cerevisiae engineered with rational strategies such as co-expressing exo- and endo-inulinase gene, inactivated proteases between haploid and diploid was investigated for inulin utilization to produce ethanol. Ethanol fermentation from $200 \mathrm{~g} / \mathrm{L}$ inulin and $250 \mathrm{~g} / \mathrm{L}$ raw Jerusalem artichoke tuber powder resulted in productivity of 2.44 and $3.13 \mathrm{~g} / \mathrm{L} / \mathrm{h}$, respectively [97]. Actually, in addition to building engineering strains, some yeast genus, such as Kluyveromyces fragilis and Kluyveromyces marxianus can both produce inulinase and ethanol. Rosa et al. selected $K$. marxianus to utilize extracted juice of Jerusalem artichoke tubers for ethanol production, the production of $12.8 \%(\mathrm{v} / \mathrm{v})$ of ethanol in $70 \mathrm{~h}$ with the consumption of $95 \%$ of initial sugars, and an ethanol yield $77 \%$ of the theoretical maximum were achieved [98]. Yuan et al. studied ethanol fermentation of $K$. marxianus ATCC8554 using inulin as substrate and the highest ethanol yield of $91.5 \%$ of the theoretical value was achieved [99]. Above all, we believe that the use of Jerusalem artichoke in ethanol fermentation will become more economical and practical.

\section{Biodiesel}

Compared with bioethanol, biodiesel has a higher heating value and lower water absorption, and can be used directly in vehicles without engine modification [100]. Cheng et al. determined the feasibility of Jerusalem artichoke tubers as feedstock for biodiesel preparation, expecting to reduce the cost of microalgal cultivation for bio-oil and biodiesel production [101]. In their study, Jerusalem artichoke hydrolysate was used as carbon sources for lipids accumulation by Chlorella protothecoides. After 4-day scale cultivation, the lipid concentration of $44 \%$ by dry mass was extracted and turned into biodiesel by transesterification. The biodiesel contained oleic acid methyl ester, linoleic acid methyl ester, and cetane acid methyl ester as the main components. Zhao et al. also reported on lipid production from Jerusalem artichoke tubers using the oleaginous yeast, Rhodosporidium toruloides $\mathrm{Y} 4$. The lipid titer of $39.6 \mathrm{~g} / \mathrm{L}$ and cellular lipid content of $56.5 \%(\mathrm{w} / \mathrm{w})$ were obtained when Jerusalem artichoke hydrolysates were fed [102]. Sung et al. used a lab yeast strain of Cryptococcus sp. and achieved lipid productivity of $1.73 \mathrm{~g} / \mathrm{L} / \mathrm{d}$ after optimization [103]. These studies suggest the feasibility of an alternative method of producing biodiesel from Jerusalem artichoke tubers using microalgal cultivation, where a cost reduction of carbon source feed in algal oil production can be expected.

\section{2,3-Butanediol}

2,3-Butanediol (2,3-BD) is an attractive chemical which can be used as a starting material for the manufacture of bulk chemicals such as 1,3-butadiene, methyl ethyl ketone, and so on [104]. As an important platform chemical, the production of 2,3-BD is mainly by chemical or biotechnological methods. With the depletion of crude 
oil, biotechnological production of 2,3-BD has received more and more attention [105]. Recently, several strains of bacteria and fungi are considered to produce 2,3-BD, including Aeromonas hydrophila, Klebsiella oxytoca, Pseudomonas hydrophila, Trichoderma harzianum, $\mathrm{K}$. pneumoniae, and B. polymyxa [106]. From an economic point of view, Fages et al. were the first to utilize Jerusalem artichoke tubers as the cheap raw material on efficient 2,3-BD production with B. polymyxa ATCC 12321. By optimizing $k_{\mathrm{L}} a$ profile, $44 \mathrm{~g} / \mathrm{L}$ of $2,3-\mathrm{BD}$ with a productivity of $0.79 \mathrm{~g} / \mathrm{L} / \mathrm{h}$ was obtained during batch culture [107]. Unfortunately, since then, little attention was paid to the microbial production of 2,3-BD from Jerusalem artichokes. Until 2009, separate hydrolysis and fermentation (SHF) and simultaneous saccharification and fermentation (SSF) were successfully introduced to 2,3-BD production by $K$. pneumoniae from Jerusalem artichoke tubers. In batch SHF process, the high concentration of fructose caused substrate inhibition for growth of cells and target products accumulation, leading to a low 2,3BD productivity of $1.08 \mathrm{~g} / \mathrm{L} / \mathrm{h}$ while SSF, which was preferable for 2,3-BD production with high concentration $(84.03 \mathrm{~g} / \mathrm{L})$ and productivity $(2.1 \mathrm{~g} / \mathrm{L} \mathrm{h})$ in fed-batch process [108]. Around the same time, Li et al. also reported that fed-batch SSF using K. pneumoniae was successfully performed, and $80.5 \mathrm{~g} / \mathrm{L}$ of target products (2,3-butanediol and acetoin) were obtained by a stage-shift aeration strategy after $68 \mathrm{~h} \mathrm{[109].} \mathrm{Li} \mathrm{et} \mathrm{al.} \mathrm{also} \mathrm{reported} \mathrm{that}$ fed-batch SSF using $K$. pneumoniae was successfully performed, and $80.5 \mathrm{~g} / \mathrm{L}$ of target products (2,3-butanediol and acetoin) were obtained by a stage-shift aeration strategy after $68 \mathrm{~h}$ and used the thermophilic Bacillus licheniformis ATCC 14580 for 2,3-BD production from inulin, with the yield of $103.0 \mathrm{~g} / \mathrm{L}$ in $30 \mathrm{~h}$ by fed-batch SSF [105]. This is the highest 2,3-BD production reported by utilizing inulin as the substrate nowadays. However, all the above studies needed separate processes to hydrolyze inulin of Jerusalem artichoke or exogenous inulinase added for 2,3-BD production. On the other hand, some 2,3-BD producers of Paenibacillus polymyxa were proven capable of fermenting inulin without previous hydrolysis. Gao et al. developed a one-step fermentation technique of raw inulin extracts from Jerusalem artichoke tubers by $P$. polymyxa ZJ-9 to produce (R,R)-2,3-BD. Under optimal conditions, the concentration of obtained (R,R)-2,3-BD reached $36.92 \mathrm{~g} / \mathrm{L}$, at more than $98 \%$ optical purity [110]. This process greatly decreased the cost and facilitated its practical application in 2,3-BD production. By genetic engineering technologies, the future work on manufacturing and modifying the industrial strains could have economic benefit on (R,R)-2,3-BD production.

\section{Lactic acid}

As an important platform chemical, lactic acid has been widely used in the many fields such as food, pharmaceutical, and chemical industries. In order to construct a cheap and energy-efficient process for lactic acid production, a variety of work has been undertaken for inexpensive raw substrates. As early as 1942, Andersen and Greaves utilized Jerusalem artichoke tubers to produce D-lactic acid [111]; however, by the 21st century, more researchers have begun to pay attention to the production of L-lactic acid using Jerusalem artichokes. Ge et al. creatively used a mixed-culture fermentation process, where A. niger SL-09 and Lactobacillus sp. G-02 were used to directly form L-lactic acid from Jerusalem artichoke tubers. The inoculation of L-lactic acid-producing strain Lactobacillus sp. G-02 greatly enhanced inulinase and invertase from $A$. niger SL-09, leading to the highest L-lactic acid concentration of $120.5 \mathrm{~g} / \mathrm{L}$ with a high conversion efficiency of $94.5 \%$ after $36 \mathrm{~h}$ of fed-batch fermentation [112]. In their study, inulinase activity was subjected to product inhibition in SSF, whereas fermentation activity of Lactobacillus casei G-02 was subjected to substrate inhibition. To further enhance lactic acid productivity, Ge et al. supplemented the media with sodium citrate to maximize the specific growth and fructose consumption rates of $L$. casei G-02. As a result, a L-lactic acid yield of $141.5 \mathrm{~g} / \mathrm{L}$ after $30 \mathrm{~h}$ was obtained by supplement of $10 \mathrm{~g} / \mathrm{L}$ sodium citrate when inoculated a $10 \%$ volume of $L$. casei G-02 [113]. Shi et al. provided a way of producing L-lactic acid by immobilized cells. A fibrousbed bioreactor was used to immobilized Lactococcus lactis cells for L-lactic acid production from hydrolysates of Jerusalem artichoke. The maximum L-lactic acid concentration of $142 \mathrm{~g} / \mathrm{L}$ was obtained in the fed-batch fermentation [114]. Choi et al. found Lactobacillus paracasei KCTC13169 could more efficiently ferment Jerusalem artichoke tubers than other Lactobacillus spp. $92.5 \mathrm{~g} / \mathrm{L}$ of lactic acid was achieved by a direct fermentation from Jerusalem artichoke extracts at $111.6 \mathrm{~g} / \mathrm{L}$ of sugar content without acidic or enzymatic inulin hydrolysis. The conversion efficiency of inulin to lactic acid reached 98\% of theoretical yield [115]. Recently, Wang et al. managed to obtain high-optical purity of L-lactate from hydrolysates of Jerusalem artichoke powder by using a thermophilic bacterium, Bacillus coagulans XZL4; a concentration of $134 \mathrm{~g} / \mathrm{L}$ of L-lactic acid was obtained and the optical purity of the final product was 99\% [116]. With further research, utilizing Jerusalem artichokes for lactic acid production will become more significant for industrialization. 
Table 3 Reports on high yields of products biorefined from Jerusalem artichoke

\begin{tabular}{|c|c|c|c|}
\hline Products & Strain and engineering targets or strategies & Yield & References \\
\hline \multirow[t]{8}{*}{ Fructooligosaccharides } & Endo-inulinase from Streptomyces rochei & $70 \%$ & [56] \\
\hline & Endo-inulinase from Pseudomonas sp. & $75.6 \%$ & [82] \\
\hline & Soluble and immobilized endo-inulinase from Pseudomonas sp. & $83 \%$ & [83] \\
\hline & Endo-inulinase from Xanthomonas sp. & $86 \%$ & [57] \\
\hline & A dual endo-inulinase system originated from Xanthomonas sp. and Pseudomonas sp. & $92 \%$ & [84] \\
\hline & Endo-inulinase from Aspergillus ficuum expressed in Escherichia coli BL21 (DE3) & $94.41 \%$ & [87] \\
\hline & $\begin{array}{l}\text { The displayed endo-inulinase from Pseudomonas mucidolens on the cells of Saccharomyces } \\
\text { cerevisiae }\end{array}$ & $71.2 \%$ & [88] \\
\hline & Endo-inulinase from Aspergillus niger expressed in Pichia pastoris & $91.3 \%$ & [89] \\
\hline \multirow[t]{12}{*}{ Ethanol } & Saccharomyces cerevisiae KCCM50549 & $36.2 \mathrm{~g} / \mathrm{L}$ & [29] \\
\hline & Saccharomyces cerevisiae Bc16a mixed with Kluyveromyces fragilis ŁOCK 0027 & $74.2 \mathrm{~g} / \mathrm{L}$ & [126] \\
\hline & Zymomonas mobilis 3881 & $78.1 \mathrm{~g} / \mathrm{L}$ & [127] \\
\hline & Zymomonas mobilis TISTR 548 & $79.8 \mathrm{~g} / \mathrm{L}$ & [91] \\
\hline & Saccharomyces cerevisiae MK01 engineered with inulinase expression through cell surface display & $89.3 \mathrm{~g} / \mathrm{L}$ & [128] \\
\hline & Kluyveromyces marxianus ATCC8554 & $93.4 \mathrm{~g} / \mathrm{L}$ & [99] \\
\hline & An Engineered Saccharomyces cerevisiae JZH & $95.19 \mathrm{~g} / \mathrm{L}$ & [97] \\
\hline & Saccharomyces sp. W0 & $95.5 \mathrm{~g} / \mathrm{L}$ & [95] \\
\hline & Zymomonas mobilis TRSTR548 & $95.9 \mathrm{~g} / \mathrm{L}$ & [129] \\
\hline & Kluyveromyces cicerisporus & $96.3 \mathrm{~g} / \mathrm{L}$ & [130] \\
\hline & Saccharomyces cerevisiae DTN & $109.4 \mathrm{~g} / \mathrm{L}$ & [131] \\
\hline & Saccharomyces cerevisiae Z-06 mixed with Aspergillus niger SL-09 & $154.7 \mathrm{~g} / \mathrm{L}$ & [94] \\
\hline \multirow[t]{3}{*}{ Biodiesel } & Chlorella protothecoides using hydrolysate of Jerusalem artichoke & $7.1 \mathrm{~g} / \mathrm{L}$ & [100] \\
\hline & Rhodotorula mucilaginosa TJY15a & $10.2 \mathrm{~g} / \mathrm{L}$ & [132] \\
\hline & Rhodosporidium toruloides Y4 & $39.6 \mathrm{~g} / \mathrm{L}$ & [102] \\
\hline \multirow[t]{5}{*}{ 2,3-Butanediol } & Paenibacillus polymyxa ZJ-9 & $36.92 \mathrm{~g} / \mathrm{L}$ & [110] \\
\hline & Bacillus polymyxa ATCC 12321 & $44 \mathrm{~g} / \mathrm{L}$ & [107] \\
\hline & Klebsiella pneumoniae & $91.63 \mathrm{~g} / \mathrm{L}$ & [108] \\
\hline & Bacillus licheniformis ATCC 14580 & $103.0 \mathrm{~g} / \mathrm{L}$ & [105] \\
\hline & A recombinant Bacillus sp. strain BRC1 with increased inulinase activity & $28.6 \mathrm{~g} / \mathrm{L}$ & [133] \\
\hline \multirow[t]{5}{*}{ Lactic acid } & Lactobacillus paracasei KCTC 13169 & $92.5 \mathrm{~g} / \mathrm{L}$ & [115] \\
\hline & Aspergillus niger SL-09 and Lactobacillus sp. G-02 & $120.5 \mathrm{~g} / \mathrm{L}$ & [112] \\
\hline & Bacillus coagulans XZL4 & $134 \mathrm{~g} / \mathrm{L}$ & [116] \\
\hline & Lactobacillus casei G-02 & $141.5 \mathrm{~g} / \mathrm{L}$ & [113] \\
\hline & Immobilized Lactococcus lactis cells in a fibrous-bed bioreactor system & $142 \mathrm{~g} / \mathrm{L}$ & [114] \\
\hline \multirow[t]{3}{*}{ Acetone-butanol } & Clostridium saccharobutylicum DSM 13864 & $9.6 \mathrm{~g} / \mathrm{L}$ & [119] \\
\hline & Clostridium acetobutylicum & $23.0-24.0 \mathrm{~g} / \mathrm{L}$ & {$[117]$} \\
\hline & Clostridium acetobutylicum L7 & $11.21 \mathrm{~g} / \mathrm{L}$ & [118] \\
\hline \multirow[t]{2}{*}{ Sorbitol } & Zymomonas mobilis ATCC 31821 & $26 \mathrm{~g} / \mathrm{L}$ & [121] \\
\hline & Saccharomyces cerevisiae ATCC 36859 & $46 \mathrm{~g} / \mathrm{L}$ & [120] \\
\hline Butyric acid & Clostridium tyrobutyricum ZJU 8235 & $60.4 \mathrm{~g} / \mathrm{L}$ & [122] \\
\hline Propionic acid & Propionibacterium acidipropionici ATCC 4875 & $26.2 \mathrm{~g} / \mathrm{L}$ & [123] \\
\hline Succinic acid & Actinobacillus succinogenes $130 Z$ & $52.7 \mathrm{~g} / \mathrm{L}$ & [124] \\
\hline Poly-(L-malic acid) & Aureobasidium pullulans $\mathrm{HA}-4 \mathrm{D}$ & $117.502 \mathrm{~g} / \mathrm{L}$ & [125] \\
\hline Poly-(Y-glutamic acid) & Bacillus amyloliquefaciens NX-2S & $39.4 \mathrm{~g} / \mathrm{L}$ & [28] \\
\hline
\end{tabular}

\section{Other bio-based products}

In addition to the above-mentioned bio-based products, other high value-added intermediate products have been gradually used in the commercial biorefining of
Jerusalem artichoke (Table 3). As early as 1985, Marchal et al. investigated acetone-butanol fermentation of Jerusalem artichoke, and used optimized conditions to obtain solvent productions of $23-24 \mathrm{~g} / \mathrm{L}$ after $36 \mathrm{~h}$ [117]. Chen 
et al. investigated butanol production from acid hydrolysates of Jerusalem artichoke juice by using Clostridium acetobutylicum L7; butanol production of this fermentation system reached $11.21 \mathrm{~g} / \mathrm{L}$, and the ratio of butanol to acetone to ethanol was 0.64:0.29:0.05 [118]. Sarchami and Rehmann optimized enzymatic hydrolysis of inulin from Jerusalem artichoke tubers for fermentative butanol production, and achieved an acetone-butanol-ethanol yield of $0.33 \mathrm{~g} / \mathrm{g}$ sugar [119]. Duvnjak et al. were the first to demonstrate the possible use of Jerusalem artichokes for sorbitol production by $S$. cerevisiae ATCC 36859; sorbitol production started after the glucose was entirely consumed from Jerusalem artichoke juice, and when the juice was supplemented with $3 \%$ yeast extract, the concentration of sorbitol reached $4.6 \%[120,121]$. In the study, butyric acid production by immobilized Clostridium tyrobutyricum was successfully performed in a fibrous-bed bioreactor (FBB) from Jerusalem artichoke hydrolysates. The high butyric acid concentration of $60.4 \mathrm{~g} / \mathrm{L}$ was obtained during fed-batch fermentation [122]. Similarly, to enhance propionic acid production from Jerusalem artichoke hydrolysate [123], Gunnarsson et al. investigated the potential of Jerusalem artichoke tuber hydrolysates for succinic acid production using Actinobacillus succinogenes 130Z. The concentration of succinic acid reached $52.7 \mathrm{~g} / \mathrm{L}$, indicating that Jerusalem artichoke as a feedstock is suitable for succinic acid production by A. succinogenes. Jerusalem artichoke is also used in the production of biocompatible and degradable polymer materials [124]. Xia et al. used Jerusalem artichoke hydrolysates for co-production of poly-(L-malic acid) and pullulan by Aureobasidium pullulans HA-4D which resulted in poly-(L-malic acid) concentration of $117.502 \mathrm{~g} / \mathrm{L}$ and pullulan concentration of $15.202 \mathrm{~g} / \mathrm{L}$ in a $1 \mathrm{t}$ bioreactor [125]. A novel strain Bacillus amyloliquefaciens NX-2S was isolated for production of poly- $(\gamma-$ glutamic acid) by Qiu et al. [28]. The NX-2S strain can assimilate inulin more efficiently than other carbohydrates from Jerusalem artichoke without hydrolytic treatment, and a yield of $39.4 \mathrm{~g} / \mathrm{L}$ poly- $(\gamma$-glutamic acid $)$ was achieved. This was also the first report that utilized Jerusalem artichoke for production of macromolecular compounds.

\section{Conclusions and future prospects}

With the rapid development of synthetic biology, more high value-added natural products and chemicals are being designed and synthesized by modular processing of metabolic pathways, and assembly and optimization of chassis. In the future, multi-products will be produced by synthetic biological processes, which will lead to huge consumptions of carbohydrate resources. Undoubtedly, using Jerusalem artichoke as a representative non-grain raw material would be an excellent place to start. It is necessary to construct a cell factory for the efficient use of inulin, to be further used as a highly efficient refining platform for the production of a variety of biologically important natural products and synthetic compounds.

For non-food raw materials, the Jerusalem artichoke has unique advantages, such as salt and drought tolerance, and strong adaptability to soil-especially for cultivation in saline-alkaline soils or coastal shoals for ecological environment protection. Meanwhile, as a promising feedstock for bioproduct synthesis, the inulin-containing crop has a high potential for use in the inulin extraction process. Although recent research on Jerusalem artichoke biorefinery is presented in this review, there is less industrial coverage. Key obstacles are how to improve inulinase activity and reduce cost, which remain the major limiting factors of the process. In high-throughput technology and protein engineering, high-activity inulinase resources are still underexploited when it comes to improving biorefinery efficiency. Furthermore, extensive research can be conducted to enhance the fermentation process through a variety of approaches, such as optimization of fermentation parameters, inulinase immobilization technologies, and advanced bioreactor designs for improving the efficiency of Jerusalem artichoke refinery products. This article reviewed the research progress on various Jerusalem artichoke components and discussed their feasibility for future biorefining of Jerusalem artichoke. We hope that this review will contribute to the industrialization of Jerusalem artichoke biorefinery.

\section{Abbreviations}

DP: degree of polymerization; FOSs: fructooligosaccharides; 2,3-BD: 2,3-Butanediol; SHF: separate hydrolysis and fermentation; SSF: simultaneous saccharification and fermentation.

\section{Authors' contributions}

YBQ and PL wrote the manuscript. Both authors read and approved the final manuscript.

\section{Author details \\ ${ }^{1}$ College of Food Science and Light Industry, Nanjing Tech University, Nan- jing 211816, China. ${ }^{2}$ Nanjing Institute for Comprehensive Utilization of Wild Plants, Nanjing 210042, China. ${ }^{3}$ Jiangsu National Synergetic Innovation Center for Advanced Materials, Nanjing Tech University, Nanjing 211816, China. \\ Acknowledgements \\ This work was funded by the National Nature Science Foundation of China (No. 21506098), the Natural Science Foundation of the Jiangsu (No. BK20150946), the Nature Science Foundation (NO. 21776133), the Nanchang Hongcheng Specialist Project, the Six Talent Peaks Project in Jiangsu Province (2016-SWYY-027), and Qing Lan Project.}

\section{Competing interests}

The authors declare that they have no competing interests. 
Ethics approval and consent to participate

Not applicable.

\section{Publisher's Note}

Springer Nature remains neutral with regard to jurisdictional claims in published maps and institutional affiliations.

Received: 2 March 2018 Accepted: 23 May 2018

Published online: 01 June 2018

\section{References}

1. Kays SJ, Nottingham SF. Biology and chemistry of Jerusalem artichoke: (Helianthus tuberosus L.). J Agric Food Inf. 2007;10:352-3.

2. Tum J. Determination of the causes of secondary salinization in Kibwezi. Doctoral dissertation, University of Nairobi. 1996.

3. Long X, Huang Z, Zhang Z, et al. Seawater stress differentially affects germination, growth, photosynthesis, and ion concentration in genotypes of Jerusalem artichoke (Helianthus tuberosus L.). J Plant Growth Regul. 2010;29:223-31.

4. Zhao GX, Yu-Huan LI, Chun-Da XU, et al. Relations and sustainable development of soil-human-environment in Kenli County. Soil Environ Sci. 1999:8:250-3.

5. Barclay T, Ginicmarkovic M, Cooper P, et al. Inulin-a versatile polysaccharide with multiple pharmaceutical and food chemical uses. J Excipients and Food Chem. 2010;1:27-50.

6. Baldini M, Danuso F, Turi M, et al. Evaluation of new clones of Jerusalem artichoke (Helianthus tuberosus L.) for inulin and sugar yield from stalks and tubers. Ind Crops Prod. 2004;19:25-40.

7. Niu L, Manxia C, Xiumei G, et al. Carbon sequestration and Jerusalem artichoke biomass under nitrogen applications in coastal saline zone in the northern region of Jiangsu, China. Sci Total Environ. 2016;568:885.

8. Cepl J, Kasal P, Souckova H, et al. Non-food production of Jerusalem artichoke (Helianthus tuberosus) and possibilities of its energetic utilization. In: Actual tasks on agricultural engineering: Proceedings of the 40. International symposium on agricultural engineering, Opatija, Croatia, 21-24 February 2012. University of Zagreb Faculty of Agriculture. 2012.

9. Monti A, Amaducci MT, Venturi G. Growth response, leaf gas exchange and fructans accumulation of Jerusalem artichoke (Helianthus tuberosus L.) as affected by different water regimes. Eur J Agron. 2005;23:136-45.

10. Sreten T, Jovanka A. Nitrogen and sugar content variability in tubers of Jerusalem artichoke (Helianthus tuberosus). Genetika. 2009;41:289-95.

11. Taha HS, El-Kawy AMA, Fathalla EK. A new approach for achievement of inulin accumulation in suspension cultures of Jerusalem artichoke (Helianthus tuberosus) using biotic elicitors. J Genet Eng Biotechnol. 2012;10:33-8

12. Ustimenko G, Usanova Z, Ratushenko O. The role of leaves and shoots at different position on tuber formation in Jerusalem artichoke. IzV Timiryazevsk S-Kh Acad. 1976;3:67-76

13. MaXY, Zhang LH, Shao HB, et al. Jerusalem artichoke (Helianthus tuberosus), a medicinal salt-resistant plant has high adaptability and multiple-use values. J Med Plant Res. 2011:5:1272-9.

14. Long XH, Shao HB, Liu L, et al. Jerusalem artichoke: a sustainable biomass feedstock for biorefinery. Renew Sust Energy Rev. 2016;54:1382-8.

15. Li SZ, Chan-Halbrendt C. Ethanol production in (the) People's Republic of China: potential and technologies. Appl Energy. 2009;86:S162-9.

16. Gunnarsson IB, Svensson SE, Johansson E, et al. Potential of Jerusalem artichoke (Helianthus tuberosus L.) as a biorefinery crop. Ind Crops Prod. 2014;56:231-40

17. Kaldy MS, Johnston A, Wilson DB. Nutritive value of Indian bread-root, squaw-root, and Jerusalem artichoke. Econ Bot. 1980:34:352-7.

18. Szambelan $\mathrm{K}$, Nowak J, Jelen $\mathrm{H}$. The composition of Jerusalem artichoke (Helianthus tuberosus L.) spirits obtained from fermentation with bacteria and yeasts. Eng Life Sci. 2010;5:68-71.

19. Wei L, Wang J, Zheng $X$, et al. Studies on the extracting technical conditions of inulin from Jerusalem artichoke tubers. J Food Eng. 2007:79:1087-93.
20. Yi H, Zhang L, Hua C, et al. Extraction and enzymatic hydrolysis of inulin from Jerusalem artichoke and their effects on textural and sensorial characteristics of yogurt. Food Bioprocess Technol. 2010;3:315-9.

21. Nasab EE, Habibirezaei M, Khaki A, et al. Investigation on acid hydrolysis of inulin: a response surface methodology approach. Int J Food Eng. 2009;5(3):64-7.

22. Xu Q, Zang Y, Zhou J, et al. Highly efficient production of D-lactic acid from chicory-derived inulin by Lactobacillus bulgaricus. Bioprocess Biosyst Eng. 2016:39(11):1-9.

23. Barthomeuf C, Regerat F, Pourrat H. Production of inulinase by a new mold of Penicillium rugulosum. J Ferment Bioeng. 1991;72:491-4.

24. Sarchami T, Rehmann L. Optimizing enzymatic hydrolysis of inulin from Jerusalem artichoke tubers for fermentative butanol production. Biomass Bioenerg. 2014;69(10):175-82.

25. Singh RS, Singh RP, Kennedy JF. Immobilization of yeast inulinase on chitosan beads for the hydrolysis of inulin in a batch system. Int J Biol Macromol. 2017;95:87-93

26. Szambelan K, Nowak J, Chrapkowska KJ Comparison of bacterial and yeast ethanol fermentation yield from Jerusalem artichoke [Helianthus tuberosus L.] tuberus pulp and juices. Acta Sci Pol Technol Aliment. 2004;1:45-53.

27. Li K, Qin JC, Liu CG, et al. Optimization of pretreatment, enzymatic hydrolysis and fermentation for more efficient ethanol production by Jerusalem artichoke stalk. Bioresour Technol. 2016;221:188-94.

28. Qiu Y, Sha Y, Zhang Y, et al. Development of Jerusalem artichoke resource for efficient one-step fermentation of poly-( $\gamma$-glutamic acid) using a novel strain Bacillus amyloliquefaciens NX-2S. Bioresour Technol. 2017;239:197-203.

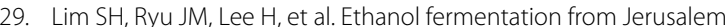
artichoke powder using Saccharomyces cerevisiae KCCM50549 without pretreatment for inulin hydrolysis. Bioresour Technol. 2011:102:2109-11.

30. Neagu C, Bahrim G. Inulinases-a versatile tool for biotechnology. Innov Rom Food Biotechnol. 2011:9:1-11.

31. Castro GR, Baigorí MD, Siñeriz F. A plate technique for screening of inulin degrading microorganisms. J Microbiol Methods. 1995;22:51-6.

32. Kango N. Production of inulinase using tap roots of dandelion (Taraxacum officinale) by Aspergillus niger. J Food Eng. 2008;85:473-8.

33. Ge XY, He Q, Zhang WG. Enhancement of fructanohydrolase synthesis from Aspergillus niger by simultaneous in vitro induction and in vivo acid stress using sucrose ester. World J Microbiol Biotechnol. 2008;24:133-8.

34. Singh RS, Sooch BS, Puri M. Optimization of medium and process parameters for the production of inulinase from a newly isolated Kluyveromyces marxianus YS-1. Bioresour Technol. 2007;98:2518-25.

35. Silva-Santisteban BOY, Filho FM. Agitation, aeration and shear stress as key factors in inulinase production by Kluyveromyces marxianus. Enzyme Microb Technol. 2005;36:717-24.

36. Sheng J, Chi Z, Li J, et al. Inulinase production by the marine yeast Cryptococcus aureus G7a and inulin hydrolysis by the crude inulinase. Process Biochem. 2007;42:805-11.

37. Fang G, Sheng J, Chi Z, et al. Inulinase production by a marine yeast Pichia guilliermondii and inulin hydrolysis by the crude inulinase. J Ind Microbiol Biotechnol. 2007:34:179.

38. Yu X, Guo N, Chi Z, et al. Inulinase overproduction by a mutant of the marine yeast Pichia guilliermondii using surface response methodology and inulin hydrolysis. Biochem Eng J. 2009;43:266-71.

39. Gao W, Ren H, Bao Y, et al. Screening and identification of thermophilic Bacillus smithii T7 for producing inulinase. 2007 enzyme engineering conference. 2007.

40. Singh RS, Chauhan K, Kennedy JF. A panorama of bacterial inulinases: production, purification, characterization and industrial applications. Int Jiol Macromol. 2017:96:312-22.

41. Spiro RG. [1] Analysis of sugars found in glycoproteins. Methods Enzymol. 1966:8:3-26.

42. Laloux O, Cassart JP, Delcour J, et al. Cloning and sequencing of the inulinase gene of Kluyveromyces marxianus var. marxianus ATCC 12424. FEBS Lett. 1991;289:64-8.

43. Wen T, Liu F, Huo K, et al. Cloning and analysis of the inulinase gene from Kluyveromyces cicerisporus CBS4857. World J Microbiol Biotechnol. 2003;19:423-6. 
44. Yedahalli SS, Rehmann L, Bassi A. Expression of exo-inulinase gene from Aspergillus niger 12 in E. coli strain Rosetta-gami B (DE3) and its characterization. Biotechnol Progr. 2016;32:629-37.

45. Demeulle S, Guiraud JP, Galzy P. Study of inulase from Debaryomyces phaffii Capriotti. J Basic Microbiol. 1981;21:181-9.

46. Gupta AK, Singh DP, Kaur N, et al. Production, purification and immobilisation of inulinase from Kluyveromyces fragilis. J Chem Technol Biotechnol. 1994;59:377-85.

47. Singh RS, Dhaliwal R, Puri M. Partial purification and characterization of exoinulinase from Kluyveromyces marxianus YS-1 for preparation of high-fructose syrup. J Microbiol Biotechnol. 2007;17:733-8.

48. Chen XM, Xu XM, Jin ZY, et al. Expression of an exoinulinase gene from Aspergillus ficuum in Escherichia coli and its characterization. Carbohydr Polym. 2013;92:1984-90.

49. Gill PK, Manhas RK, Singh P. Purification and properties of a heat-stable exoinulinase isoform from Aspergillus fumigatus. Bioresour Technol. 2006;97:894-902.

50. Kwon YM, Kim HY, Choi YJ. Cloning and characterization of Pseudomonas mucidolens exoinulinase. J Microbiol Biotechnol. 2000:10:238-43.

51. Nagem RA, Rojas AL, Golubev AM, et al. Crystal structure of exoinulinase from Aspergillus awamori: the enzyme fold and structural determinants of substrate recognition. J Mol Biol. 2004;344:471-80.

52. Goosen C, Van Der Maarel MJ, Dijkhuizen L. Exo-inulinase of Aspergillus niger N402: A hydrolytic enzyme with significant transfructosylating activity. Biocatal Biotransform. 2008:26:49-58.

53. Nakamura T, Shitara A, Matsuda S, et al. Production, purification and properties of an endoinulinase of Penicillium sp. TN-88 that liberates inulotriose. J Ferment Bioeng. 1997;84:313-8.

54. Mutanda T, Wilhelmi BS, Whiteley CG. Response surface methodology: synthesis of inulooligosaccharides with an endoinulinase from Aspergillus niger. Enzyme Microb Tech. 2008;43:362-8.

55. Li Y, Liu GL, Wang K, et al. Overexpression of the endo-inulinase gene from Arthrobacter sp. S37 in Yarrowia lipolytica and characterization of the recombinant endo-inulinase. J Mol Catal B Enzym. 2012;74:109-15.

56. Yokota A, Yamauchi O, Tomita F. Production of inulotriose from inulin by inulin-degrading enzyme from Streptomyces rochei E87. Lett Appl Microbiol. 1995:21:330-3.

57. Park JP, Bae JT, You DJ, et al. Production of inulooligosaccharides from inulin by a novel endoinulinase from Xanthomonas sp. Biotechnol Lett. 1999;21:1043-6.

58. Ohta K, Akimoto H, Matsuda S, et al. Molecular cloning and sequence analysis of two endoinulinase genes from Aspergillus niger. Biosci Biotechnol Biochem. 1998:62:1731-8.

59. Liu GL, Chi Z, Chi ZM. Molecular characterization and expression of microbial inulinase genes. Crit Rev Microbiol. 2013;39:152-65.

60. Kim KY, Nascimento AS, Golubev AM, et al. Catalytic mechanism of inulinase from Arthrobacter sp S37. Biochem Biophys Res Commun. 2008:371:600-5

61. SouzaMotta CMD, Cavalcanti MADQ, et al. Aspergillus niveus Blochwitz 4128URM: new source for inulinase production. Braz Arch Biol Technol. 2005:48:343-50

62. Peng Y. Production, optimization and properties of exo-nulinase by Aspergillus ficuum SKO04. Food and Ferment Ind. 2005;31:61-5.

63. Astolfi $V$, Joris J, Verlindo R, et al. Operation of a fixed-bed bioreactor in batch and fed-batch modes for production of inulinase by solid-state fermentation. Biochem Eng J. 2011;58:39-49.

64. Chen $\mathrm{HQ}$, Chen XM, Yin L, et al. Purification and characterisation of exo- and endo-inulinase from Aspergillus ficuum JNSP5-06. Food Chem. 2009:115:1206-12.

65. Singh RS, Singh RP, Kennedy JF. Endoinulinase production by a new endoinulinase producer Aspergillus tritici BGPUP6 using a low cost substrate. Int J Biol Macromol. 2016;92:1113.

66. Xiong C, Wang J, Li D. Optimization of solid-state medium for the production of inulinase by Kluyveromyces S120 using response surface methodology. Biochem Eng J. 2007:34:179-84.

67. Kong $L$, Shi Y, Chen X. Enzymatic properties of inulinase from Kluyveromyces S120. Food Res Dev. 2012:33:165-7.
68. Onagar B, Silva-Santisteban Y, Converti A, et al. Intrinsic activity of inulinase From Kluyveromyces marxianus ATCC 16045 and carbon and nitrogen balances. Food Technol Biotechnol. 2006;44:479-83.

69. Sheng J, Chi Z, Gong F, et al. Purification and characterization of extracellular inulinase from a marine yeast Cryptococcus aureus G7a and inulin hydrolysis by the purified inulinase. Appl Biochem Biotechnol. 2008;13:533-9.

70. Sheng J, Chi Z, Yan K, et al. Use of response surface methodology for optimizing process parameters for high inulinase production by the marine yeast Cryptococcus aureus G7a in solid-state fermentation and hydrolysis of inulin. Bioprocess Biosyst Eng. 2009;32:333-9.

71. Gong F, Zhang T, Chi Z, et al. Purification and characterization of extracellular inulinase from a marine yeast Pichia guilliermondii and inulin hydrolysis by the purified inulinase. Appl Biochem Biotechnol. 2008;144:111-21.

72. Gill PK, Sharma AD, Harchand RK, et al. Effect of media supplements and culture conditions on inulinase production by an actinomycete strain. Bioresour Technol. 2003;87:359-62.

73. Gao J, Xu YY, Yang HM, et al. Gene cloning, expression, and characterization of an exo-inulinase from Paenibacillus polymyxa ZJ-9. Appl Biochem Biotechnol. 2014;173:1419-30.

74. Kang SI, Kim Sl, Kim KY. Production of a novel endo-inulinase from Arthrobacter sp. S37. Agric Chem Biotechnol. 1996;39:99-103.

75. Kang Sl, Chang YJ, Oh SJ, et al. Purification and properties of an endoinulinase from an Arthrobacter sp. Biotechnol Lett. 1998;20:983-6.

76. Singh RS, Singh RP. Response surface optimization of endoinulinase production from a cost effective substrate by Bacillus safensis AS-08 for hydrolysis of inulin. Biocatal Agric Biotechnol. 2014;3:365-72.

77. Yun JW. Fructooligosaccharides-Occurrence, preparation, and application. Enzyme Microb Technol. 1996;19:107-17.

78. Molis C, Flourié B, Ouarne F, et al. Digestion, excretion, and energy value of fructooligosaccharides in healthy humans. Am J Clin Nutr. 1996;64:324-8.

79. Prapulla SG, Subhaprada V, Karanth NG. Microbial production of oligosaccharides: a review. Adv Appl Microbiol. 2000;47:299-343.

80. Ganaie MA, Lateef A, Gupta US. Enzymatic trends of fructooligosaccharides production by microorganisms. Appl Biochem Biotechnol. 2014:172:2143-59.

81. Singh RS, Singh RP, Pandey A, et al. Production of fructooligosaccharides from inulin by endoinulinases and their prebiotic potential. Food Technol Biotechnol. 2010;48:435-50.

82. Dong HK, Yong JC, Song SK, et al. Production of inulo-oligosaccharides using endo-inulinase from a Pseudomonas sp. Biotechnol Lett. 1997;19:369-72.

83. Yun JW, Dong HK, Kim BW, et al. Production of inulo-oligosaccharides from inulin by immobilized endoinulinase from Pseudomonas sp. J Ferment Bioeng. 1997:84:369-71.

84. Cho YJ, Sinha J, Park JP, et al. Production of inulooligosaccharides from inulin by a dual endoinulinase system. Enzyme Microb Technol. 2001;29:428-33.

85. Jin Z, Wang J, Jiang B, et al. Production of inulooligosaccharides by endoinulinases from Aspergillus ficuum. Food Res Int. 2005;38:301-8.

86. Yun JW, Yong JC, Song $\mathrm{CH}$, et al. Microbial production of inulo-oligosaccharides by an endoinulinase from Pseudomonas sp. Expressed in Escherichia coli. J Biosci Bioeng. 1999:87:291-5.

87. Wang P, Ma J, Zhang Y, et al. Efficient secretory overexpression of endoinulinase in Escherichia coli and the production of inulooligosaccharides. Appl Biochem Biotechnol. 2016;179:880-94.

88. Kim HC, Kim HJ, Choi YJ, et al. Inulooligosaccharide production from inulin by Saccharomyces cerevisiae strain displaying cell-surface endoimulinase. J Microbiol Biotechnol. 2006;16:360-7.

89. $X u Y, Z$, heng $Z, X u Q$, et al. Efficient conversion of inulin to inulooligosaccharides through endoinulinase from Aspergillus niger. J Agr Food Chem. 2016:64:2612-8.

90. Bhagia S, Akinosho H, Ferreira JF, et al. Biofuel production from Jerusalem artichoke tuber inulins: a review. Biofuel Res J. 2017:4:587-99.

91. Onsoy T, Thanonkeo P, Thanonkeo S, et al. Ethanol production from Jerusalem artichoke by Zymomonas mobilis in batch fermentation. KMITL Sci Technol J. 2007;7:55-60. 
92. Lujanrhenals DE, Morawicki RO, Ricke SC. Tolerance of S. cerevisiae and Z. mobilis to inhibitors produced during dilute acid hydrolysis of soybean meal. J Environ Sci Health B. 2014;49:305-11.

93. Zhang $\mathrm{T}$, $\mathrm{Chi} \mathrm{Z}$, Zhao $\mathrm{CH}$, et al. Bioethanol production from hydrolysates of inulin and the tuber meal of Jerusalem artichoke by Saccharomyces sp. W0. Bioresour Technol. 2010;101:8166-70.

94. Ge XY, Zhang WG. A shortcut to the production of high ethanol concentration from Jerusalem artichoke tubers. Food Technol Biotechnol. 2005:43:241-6.

95. Tong Z, Zhe C, Chi Z, et al. Expression of the inulinase gene from the marine-derived Pichia guilliermondii in Saccharomyces sp. W0 and ethanol production from inulin. Microb Biotechnol. 2010;3:576-82.

96. Yuan B, Wang SA, Li FL. Expression of exoinulinase genes in Saccharomyces cerevisiae to improve ethanol production from inulin sources. Biotechnol Lett. 2013;35:1589-92.

97. Wang D, Li FL, Wang SA. Engineering a natural Saccharomyces cerevisiae strain for ethanol production from inulin by consolidated bioprocessing. Biotechnol Biofuels. 2016;9:96.

98. Rosa MF, Vieira AM, Bartolomeu ML, et al. Production of high concentration of ethanol from mash, juice and pulp of Jerusalem artichoke tubers by Kluyveromyces fragilis. Enzyme Microb Technol. 1986;8(11):673-6.

99. Yuan WJ, Zhao XQ, Ge XM, et al. Ethanol fermentation with Kluyveromyces marxianus from Jerusalem artichoke grown in salina and irrigated with a mixture of seawater and freshwater. J Appl Microbiol. 2008;105(6):2076-83.

100. Li L, Li L, Wang Y, et al. Biorefinery products from the inulin-containing crop Jerusalem artichoke. Biotechnol Lett. 2013;35:471.

101. Cheng Y, Zhou W, Gao C, et al. Biodiesel production from Jerusalem artichoke (Helianthus Tuberosus L.) tuber by heterotrophic microalgae Chlorella protothecoides. J Chem Technol Biotechnol. 2009;84:777-81.

102. Zhao X, Wu S, Hu C, et al. Lipid production from Jerusalem artichoke by Rhodosporidium toruloides Y4. J Ind Microbiol Biotechnol. 2010;37:581-5.

103. Sung M, Seo YH, Han S, et al. Biodiesel production from yeast Cryptococcus sp. using Jerusalem artichoke. Bioresour Technol. 2014;155:77.

104. Celinska E, Grajek W. Biotechnological production of 2,3-butanediolcurrent state and prospects. Biotechnol Adv. 2009;27:715-25.

105. Li L, Chen C, Li K, et al. Efficient simultaneous saccharification and fermentation of inulin to 2,3-butanediol by thermophilic Bacillus licheniformis ATCC 14580. Appl Environ Microb. 2014;80:6458-64.

106. Ji XJ, Huang H, Ouyang PK. Microbial 2,3-butanediol production: a state-of-the-art review. Biotechnol Adv. 2011:29:351-64.

107. Fages J, Mulard D, Rouquet JJ, et al. 2,3-Butanediol production from Jerusalem artichoke, Helianthus tuberosus, by Bacillus polymyxa ATCC 12321. Optimization of $k_{L}$ a profile. Appl Microbiol Biot. 1986;25:197-202.

108. Sun LH, Wang XD, Dai JY, et al. Microbial production of 2,3-butanediol from Jerusalem artichoke tubers by Klebsiella pneumoniae. Appl Microbiol Biotechnol. 2009;82:847-52.

109. Li D, Dai JY, Xiu ZL. A novel strategy for integrated utilization of Jerusalem artichoke stalk and tuber for production of 2,3-butanediol by Klebsiella pneumonia. Bioresour Technol. 2010;101:8342-7.

110. Gao J, Xu H, Li QJ, et al. Optimization of medium for one-step fermentation of inulin extract from Jerusalem artichoke tubers using Paenibacillus polymyxa ZJ-9 to produce R, R-2,3-butanediol. Bioresour Technol. 2010;101:7087.

111. Andersen AA, Greaves JE. D-lactic acid fermentation of Jerusalem artichokes. Ind Eng Chem. 1942;24(12):1522-6.

112. Ge X, Qian H, Zhang W. Improvement of L-lactic acid production from Jerusalem artichoke tubers by mixed culture of Aspergillus niger and Lactobacillus sp. Bioresour Technol. 2009;100:1872.

113. Ge XY, Qian H, Zhang WG. Enhancement of L-lactic acid production in Lactobacillus casei from Jerusalem artichoke tubers by kinetic optimization and citrate metabolism. J Microbiol Biotechnol. 2010;20:101-9.

114. Shi Z, Wei P, Zhu X, et al. Efficient production of L-lactic acid from hydrolysate of Jerusalem artichoke with immobilized cells of
Lactococcus lactis in fibrous bed bioreactors. Enzyme Microb Technol. 2012;51:263-8.

115. Choi HY, Ryu HK, Park KM, et al. Direct lactic acid fermentation of Jerusalem artichoke tuber extract using Lactobacillus paracasei without acidic or enzymatic inulin hydrolysis. Bioresour Technol. 2012;114:745-7.

116. Wang $L, X u e ~ Z, B o Z$, et al. Jerusalem artichoke powder: a useful material in producing high-optical-purity L-lactate using an efficient sugar-utilizing thermophilic Bacillus coagulans strain. Bioresour Technol. 2013:130:174-80.

117. Marchal R, Blanchet D, Vandecasteele JP. Industrial optimization of acetone-butanol fermentation: a study of the utilization of Jerusalem artichokes. Appl Microbiol Biotechnol. 1985;23:92-8.

118. Chen L, Xin C, Deng P, et al. Butanol production from hydrolysate of Jerusalem artichoke juice by Clostridium acetobutylicum L7. Chin J Biotechnol. 2010;26:991-6.

119. Sarchami T, Rehmann L. Optimizing enzymatic hydrolysis of inulin from Jerusalem artichoke tubers for fermentative butanol production. Biomass Bioenergy. 2014;69:175-82.

120. Duvnjak Z, Turcotte G, Duan ZD. Production of sorbitol and ethanol from Jerusalem artichokes by Saccharomyces cerevisiae ATCC 36859. Appl Microbiol Biotechnol. 1991;35:711-5.

121. Kim DM, Kim HS. Continuous production of gluconic acid and sorbitol from Jerusalem artichoke and glucose using an oxidoreductase of Zymomonas mobilis and inulinase. Biotechnol Bioeng. 1992;39:336-42.

122. Huang J, Cai J, Wang J, et al. Efficient production of butyric acid from Jerusalem artichoke by immobilized Clostridium tyrobutyricum in a fibrous-bed bioreactor. Bioresour Technol. 2011;102:3923-6.

123. Liang ZX, Li L, Li S, et al. Enhanced propionic acid production from Jerusalem artichoke hydrolysate by immobilized Propionibacterium acidipropionici in a fibrous-bed bioreactor. Bioprocess Biosyst Eng. 2012:35:915-21.

124. Gunnarsson IB, Karakashev D, Angelidaki I. Succinic acid production by fermentation of Jerusalem artichoke tuber hydrolysate with Actinobacillus succinogenes 130Z. Ind Crop Prod. 2014;62:125-9.

125. Xia J, Xu J, Liu X, et al. Economic co-production of poly(malic acid) and pullulan from Jerusalem artichoke tuber by Aureobasidium pullulans HA-4D. BMC Biotechnol. 2017;17:20.

126. Szambelan K, Nowak J, Czarnecki Z. Use of Zymomonas mobilis and Saccharomyces cerevisiae mixed with Kluyveromyces fragilis for improved ethanol production from Jerusalem artichoke tubers. Biotechnol Lett. 2004;26:845-8.

127. Szambelan K, Chrapkowska KJ. The influence of selected microorganisms on ethanol yield from Jerusalem artichoke (Hellianthus tuberosus L.) tubers. Pol J Food Nutr Sci. 2003;12:49-52.

128. Khatun MM, Liu CG, Zhao XQ, et al. Consolidated ethanol production from Jerusalem artichoke tubers at elevated temperature by Saccharomyces cerevisiae engineered with inulinase expression through cell surface display. J Ind Microbiol Biotechnol. 2017;44:295-301.

129. Thanonkeo P, Thanonkeo S, Charoensuk K, et al. Ethanol production from Jerusalem artichoke (Helianthus tuberosus L.) by Zymomonas mobilis TISTR548. Afr J Biotechnol. 2011;10:10691-7.

130. Yuan W, Chang B, Chen L, et al. Ethanol production from Jerusalem artichoke by SSF fermentation using Kluyveromyces cicerisporus. J Biotechnol. 2010;150:367-8.

131. Razmovski RN, Šc'iban MB, Vučurovic' VM. Bioethanol production from Jerusalem artichoke by acid hydrolysis. Rom Biotech Lett. 2011;16:6497-503.

132. Zhao $\mathrm{CH}$, Tong $\mathrm{Z}$, Mei $\mathrm{L}$, et al. Single cell oil production from hydrolysates of inulin and extract of tubers of Jerusalem artichoke by Rhodotorula mucilaginosa TJY15a. Process Biochem. 2010;45:1121-6.

133. Park JM, Oh BR, Kang IY, et al. Enhancement of 2,3-butanediol production from Jerusalem artichoke tuber extract by a recombinant Bacillus sp. strain BRC1 with increased inulinase activity. J Ind Microbiol Biotechnol. 2017:44:1-7. 